\title{
VARIANCE IN THE COURSE OF PALMAR CUTANEOUS BRANCH OF MEDIAN NERVE ALONG WITH A VARIANT HEAD OF BICEPS BRACHII - A CADAVERIC CASE REPORT.
}

Khushboo Mogra ${ }^{1}$, Rohin Garg${ }^{2}$, Sushila Shekhawat ${ }^{3}$

\section{HOW TO CITE THIS ARTICLE:}

Khushboo Mogra, Rohin Garg, Sushila Shekhawat. "Variance in the Course of Palmar Cutaneous Branch of Median Nerve along with a variant head of Biceps Brachii - A Cadaveric Case Report". Journal of Evolution of Medical and Dental Sciences 2014; Vol. 3, Issue 03, January 20; Page: 608-612,

DOI: $10.14260 / J E M D S / 2014 / 1873$

ABSTRACT: The present case report describes the variance in the course of palmar cutaneous branch of median nerve along with a variant head of biceps brachii muscle in a middle aged male cadaver during routine dissection of right \& left upper limb respectively. In the course of palmar cutaneous branch of median nerve it was observed that it was originating approx. $3 \mathrm{~cm}$ proximal to flexor retinaculum and passed beneath the flexor retinaculum instead of passing superficial to it as described in conventional anatomical textbooks. Along with it, the third head of biceps brachii was found to originate from shaft of humerus from superomedial part of brachialis and its lower end was attached to lower part of muscle belly.

KEYWORDS: palmar cutaneous branch, median nerve, third head, biceps brachii, variation.

INTRODUCTION: The anatomy of palmar cutaneous branch of median nerve has been documented by many authors. The palmar cutaneous branch arises a little above the wrist and runs on the anterior surface of the median nerve to about the upper border of flexor retinaculum, here the palmar branch become subcutaneous and the median nerve passes behind the retinaculum ${ }^{1}$. So normally, the sensory nerve supply to skin of palm is derived from palmar cutaneous branch of median nerve which crosses in front of flexor retinaculum and supplies lateral part of palm ${ }^{2}$. But in the present case, it was passing beneath the flexor retinaculum.

Biceps brachii is a large fusiform muscle in the flexor compartment of arm. Biceps brachii derives its name from its two proximally attached parts/ heads. Short head arises by a thick flattened tendon from the coracoid apex. Long head starts with in capsule of shoulder joint as a long narrow tendon, running from supraglenoid tubercle of scapula. The two tendons lead into elongated bellies that although closely applied, can be separated to within $7 \mathrm{~cm}$ or so of elbow joint. At this joint, they end in a flattened tendon which is attached to the rough part of radial tuberosity. Tendon has a broad medial expansion, bicipital aponeurosis which fuses with deep fascia of forearm ${ }^{3}$. The biceps brachii muscle along with the two heads, showed a variant third head in the present case.

CASE REPORT: During routine dissection of a middle aged male cadaver at SMS Medical College, Rajasthan, India, variation in course of palmar cutaneous branch of median nerve was observed in right upper limb. It was originating approx. $3 \mathrm{~cm}$ proximal to flexor retinaculum from the radial side of median nerve. It was running between the tendons of Palmaris longus and flexor carpi radialis and passed beneath the flexor retinaculum instead of passing superficial to it as described in conventional anatomical textbooks and became subcutaneous just distal to distal wrist crease as shown in fig 1. 
Along with this variation, it was observed that there was the presence of a third head of biceps brachii in left upper limb of the same cadaver. It has been reported previously that in $10 \%$ cases, the third head of biceps brachii may arise from superomedial part of brachialis and is attached to bicipital aponeurosis but in this case, third head of biceps brachii was found to originate from shaft of humerus from superomedial part of brachialis and its lower end was attached to lower part of muscle belly instead of bicipital aponeurosis. Its length and breadth were $11.7 \mathrm{~cm}$ and $1.8 \mathrm{~cm}$ respectively as shown in fig 2,3 , 4 . In this case, brachial artery ran medial to the third head of biceps brachii muscle. The variant head lay deeper to the medial side of bulk of usual biceps brachii muscle, innervated by a branch of musculocutaneous nerve and supplied by brachial artery.

DISCUSSION: Previous studies have been done to show the anatomy of palmar cutaneous branch of median nerve with its variations in the palm and its relationship with the other cutaneous nerves of palm. In the present study it was shown that palmar cutaneous branch originated from radial side of median nerve and passed beneath the flexor retinaculum which was similar with the work done by previous workers 4,5 . In a study done in 120 specimens of hand, it was found that in $88.5 \%$ cases palmar cutaneous branch originated from radial side of median nerve. In $31.7 \%$, it branched above flexor retinaculum; and in $40 \%$ branched under flexor retinaculum ${ }^{4}$. Julio Taleisnik observed during dissection of 12 cadaver hands that median palmar cutaneous nerve presented a fairly constant origin and course down to the variations encountered in its distal portion and in its distribution ${ }^{6}$. The variations found in palmar cutaneous branch of median nerve may become very important for hand surgeons during decompressive surgeries of carpal tunnel. Palmar cutaneous branch may be injured by a transverse incision at wrist, while the terminal fibres passing through the substance of transverse carpal ligament (flexor retinaculum) may be injured by longitudinal division of ligament during decompression. Due to this, a definitive neuroma may be formed or it may lead to prolonged and disabling dysthesias.

Third head of biceps brachii as seen in the present study was also observed previously. Conventional textbooks describes that a not uncommon anomaly of the biceps is for it to present three or more heads. In $10 \%$ cases, a $3^{\text {rd }}$ head arises from superomedial part of brachialis and is attached to bicipital aponeurosis and medial side of the tendon of insertion ${ }^{3}$.

PP Poudel and C Bhattarai studied 32 arms from 16 Nepalese cadavers. Supernumerary heads of biceps brachii were observed in $12.5 \%$ of 32 arms. Among these, three headed and four headed was present in $6.2 \%$ cases 7 .

Eiman Abdel Meguid also observed $3^{\text {rd }}$ head originating from the middle of anteromedial surface of humerus and inserting into common tendon more closely associated with short head ${ }^{8}$. Variation in biceps brachii is important since it can cause compression of surrounding neurovascular structures. Presence of third head may cause unusual bone displacement subsequent to fracture, so having relevance in surgical procedures. Presence of $3^{\text {rd }}$ head might increase its kinematics and may increase power of flexion and supination component. It may be important for surgeons operating on arm in preventing iatrogenic injuries and for clinicians diagnosing nerve impairment.

So, the variations in palmar cutaneous branch of median nerve and the variations in biceps brachii have a great value and should be kept in mind while performing various surgical procedures in a routine manner. 
ACKNOWLEDGEMENTS: I am highly thankful to Dr. Sangita Chauhan, Professor and Head of Department of Anatomy, SMS Medical College, Jaipur, Rajasthan for her support and proof reading of this case report.

\section{REFERENCES:}

1. Hollinshead W.H. Anatomy for Surgeons. Vol III. Back and Limbs. New York. Harper and Row, 1964.

2. Snell R.S. Clinical Anatomy by Regions. $9^{\text {th }}$ ed. Lippincott Williams \& Wilkins. 2012; 397-98.

3. Johnson D, Standring S. Pectoral Girdle and Upper Limb. Grays Anatomy. 40thed., Elsevier Churchill Livingstone. 2008; 825.

4. Cheung JW, Shyu JF, Teng CC, Chen TH, Su CH, Shyr YM, Wang JJ, Wu CW, Lui WY, Liu JC. The anatomical variations of the palmar cutaneous branch of the median nerve in Chinese adults. J Chin Med Assoc. 2004; 67; 27-31.

5. Naff N, Dellon AL, Mackinnon SE. The anatomical course of the palmar cutaneous branch of median nerve, including a description of its own unique tunnel. Journal of Hand surgery British and European volume. 1993, 18B; 316-317.

6. Taleisnk J. The palmar cutaneous branch of the median nerve and the approach to the carpal tunnel: An anatomical study. Journal of bone and joint surgery. 1973; 55A; 6; 1212-7.

7. Poudel PP, Bhattarani C. Study on the supernumerary heads of biceps brachii muscle in Nepalese. Nepal Med Col J. 2009; 11: 96-98.

8. Meguid EA. An anatomical study on the third head of biceps brachii in human. Alexandria faculty of medicine. $2010 ; 46 ; 1: 33-39$.

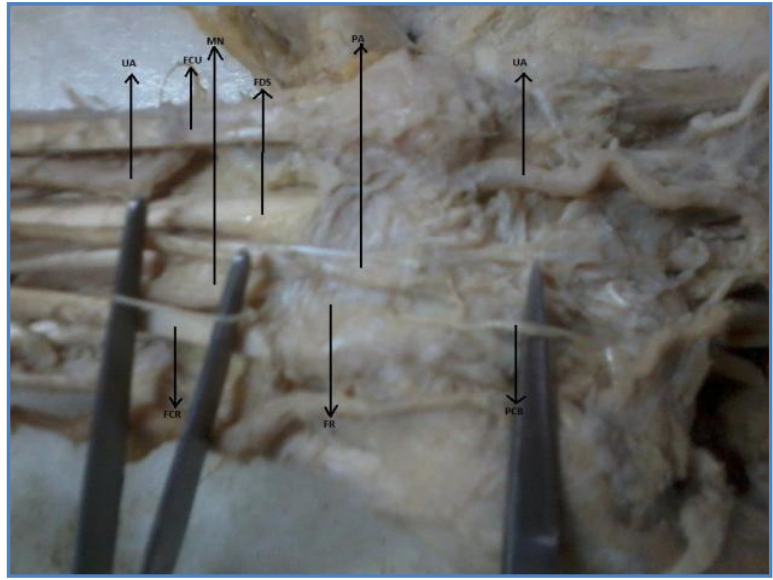

\section{Fig. 1: PCB- Palmar cutaneous branch of median nerve passing beneath the flexor retinaculum (FR).}

UA- ulnar artery

MN- median nerve

FDS- flexor digitorum superficialis tendon

FCR- flexor carpi radialis tendon

PA- Palmar aponeurosis

FCU- Flexor carpi ulnaris 


\section{CASE REPORT}

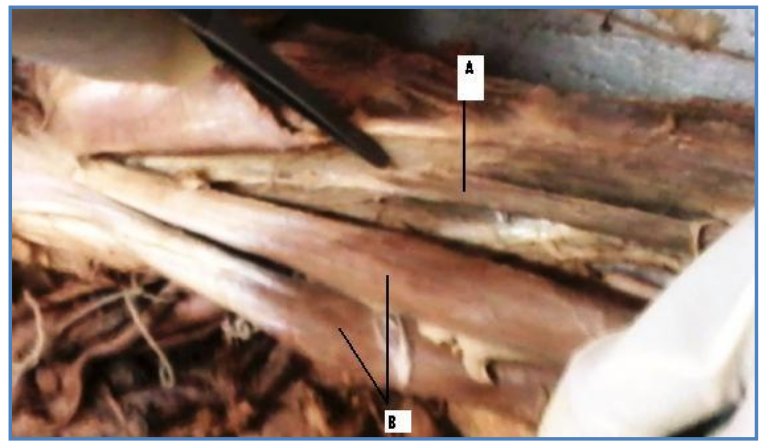

Fig. 2

A: Origin of 3rd head of biceps brachii

B: 2 heads of biceps brachii

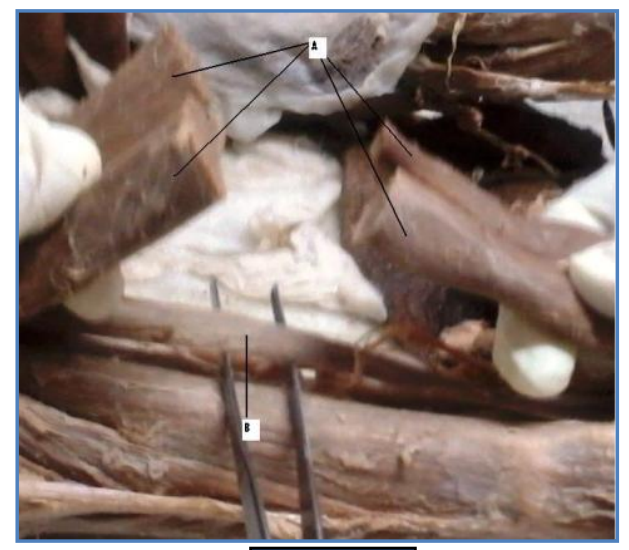

Fig. 3

A: Cut ends of 2 heads of biceps brachii reflected upwards

B: Muscle belly of $3^{\text {rd }}$ head of biceps brachii.

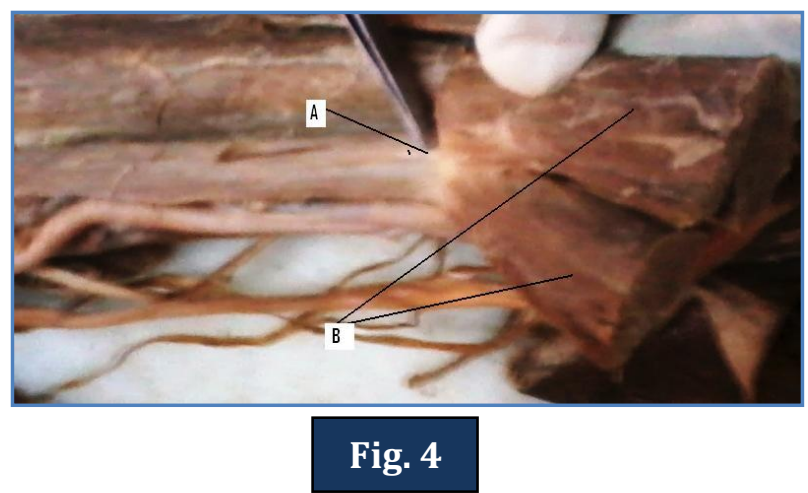

A: Insertion of $3^{\text {rd }}$ head of biceps brachii.

B: Cut ends of 2 heads of biceps brachii 


\section{CASE REPORT}

\section{AUTHORS:}

1. Khushboo Mogra

2. Rohin Garg

3. Sushila Shekhawat

\section{PARTICULARS OF CONTRIBUTORS:}

1. Resident, Department of Anatomy, SMS Medical College, Jaipur.

2. Resident, Department of Anatomy, SMS Medical College, Jaipur.

3. Senior Demonstrator, Department of Anatomy, JLN Medical College, Ajmer.
NAME ADDRESS EMAIL ID OF THE CORRESPONDING AUTHOR:

Dr. Khushboo Mogra,

C-28, Indra Vihar,

Kota (Rajasthan).

Email - khushi.mogra@gmail.com

Date of Submission: 21/12/2013.

Date of Peer Review: 23/12/2013.

Date of Acceptance: 06/01/2014.

Date of Publishing: 14/01/2014. 